\title{
How big breweries failed the taste test
}

Sir - Two points mentioned in a recent book review on beer ${ }^{1}$ deserve clarification. The term 'real ale' does need to be distinguished from other beers. Real ale refers specifically to an ale made from traditional ingredients in which carbonation is produced by means of secondary fermentation in the cask (or container) from which it is served ${ }^{2}$.

A real ale uses no external source of carbon dioxide pressure to drive beer from the cellar to the tap, but instead employs a traditional hand-operated pump called a beer engine. The result is a beer with a much lower level of carbonation than that usually encountered in other beers, which might well be loosely defined as alcoholic beverages made with water, malted barley and hops, and fermented by yeast. A real ale requires the careful management by skilled publicans of a live beer whose flavour may change subtly with each passing hour or few pints served.

The preservation and revival of this method of preparing and serving beer has been largely due to the Campaign for Real Ale (CAMRA) in England, formed in 1971.
As mentioned in the book review ${ }^{1}$, these activities have indeed led in part to the growth of this art in England, but have also played a decisive role in the evolution of the craft (pub, small/micro- and home-) brewing industry throughout the world.

Second, the brewing of mass-produced beers probably should not have been referred to as "sophisticated". Historically the largest breweries in the world were easily able to out-compete smaller breweries and public houses from the end of the prohibition years until the beginnings of the craft brewery movement by producing beer more inexpensively than smaller breweries (by virtue of the large volumes produced), and through extensive advertising campaigns. Along the way, though, the drive to increase the profit margin of beer and reduce the costs of its production led to the excessive use of brewing adjuncts (cheaper sources of fermentable sugars for yeast fermentation than malted barley) and to excessive dilution of the beers produced by means of high-gravity brewing techniques (reviewed in ref. 3).
This increased "sophistication" in the brewing industry led inevitably to consumer demand for better beers (if not indeed for 'real beer'). This worldwide trend in which beer consumers increasingly demand a quality product has led to significant losses in sales by the largest breweries, which are now making efforts to rectify this by introducing all-malt and other speciality beers to compete in this growing consumer sector. So, if anything, the "sophistication" of the large breweries has been responsible for their own misfortune.

Victor E. Buckwold

Ricardo Amils

Centro de Biología Molecular,

"Severo Ochoa" Universidad

Autónoma de Madrid,

Cantoblanco,

28049 Madrid, Spain

e-mail:vebuckwold@trasto.cbm.uam.es

1. Postgate, J. Nature 393, 129 (1998)

2. Daniels, R. Designing Great Beers: The Ultimate Guide to Brewing Classic Beer Styles (Brewers Publications, Boulder, CO, 1996).

3. Buckwold, V. E. Brewing Techniques (in the press).

\section{Bullying of $\mathrm{PhDs}$}

Sir - The 'feudal' master-servant relationship existing between a $\mathrm{PhD}$ supervisor and his or her student ${ }^{1}$ has another facet seldom broached by academics. That is bullying. Employment legislation prohibits bullying at work, but, because $\mathrm{PhDs}$ are not salaried or contracted, they are not legally 'employees' and so are vulnerable to capricious supervisors.

I regret to say that the conduct of my PhD supervisor was tantamount to bullying. Corroborative complaints by peers and by me proved futile, culminating in my supervisor misappropriating corresponding authorship after editorial review of our manuscript. Although nebulous commitments to $\mathrm{PhD}$ supervision published in guidelines are welcome, they are merely cosmetic unless enforced impartially against the occasional aberrant supervisor. Experience has left me disaffected with my university, which is ostensibly content to allow a rogue supervisor to usurp authorship and confidence by allowing vulnerable $\mathrm{PhDs}$ to be bullied.

PhDs may now, however, be able to seek alternative recourse. In an unprecedented move, the British High Court has granted a student at the University of Cambridge, Mr Beg, judicial review to challenge internal academic procedures ${ }^{2}$. Mr Beg was allegedly denied an MPhil because he criticized a professor. If future legal challenges are to be avoided, reform is required to make possible equitable adjudication in alleged cases of supervisor misconduct. If UK institutions insist on maintaining the status quo, the courts may now intervene and universities will increasingly become embroiled in unwelcome litigation ${ }^{3}$. Denying the existence of bullying could become costly. Universities competing for funding and kudos can ill-afford to risk harbouring known aggressors, thus condoning their conduct and bringing departments into disrepute.

Inevitably, 'whistleblowers' (whether on matters of personal or academic misconduct) risk damage to their careers ${ }^{4}$. To ensure scientific integrity, postgraduate students need adequate protection from the repercussions of 'speaking out'. PhDs should surely be protected from bullying and unfair termination of studentships, in the same way as 'employed' researchers are protected by legislation and contracts.

Name and address supplied

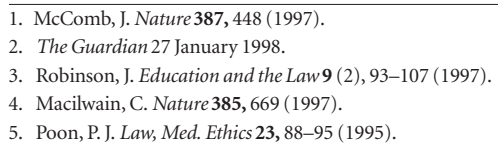

\section{Summing up a wizard at}

\section{maths... warts and all}

Sir - In his review of my book Wizard: The Life and Times of Nikola Tesla (Nature 388, 135-136; 1997), L. Pearce Williams says that "no evidence is presented that [Tesla's] mathematical competence was at the level of contemporary mathematicians or even his fellow 'electricians"'. I find this claim difficult to understand.

In 1937, Tesla was nominated for a Nobel prize in physics for his fundamental equations explaining AC polyphase systems, and his application of mathematical principles to his various inventions was acknowledged by Ambrose Fleming, Lord Kelvin, Ernest Rutherford, W. H. Eccles, Niels Bohr and Albert Einstein, among others.

Also, the statement that I "always" portray Tesla in a favourable light is incorrect. His financial deception of John Jacob Astor, his breach of contract with J. P. Morgan and his self-destructive tendencies and their link to the death of his older brother are just some of Tesla's quirks, mistakes, foibles or miscalculations that I pointed out.

Marc J. Seifer

MetaScience Productions,

Box 32,

Kingston, Rhode Island 02881, USA 